\title{
Korelasi Total Kandungan Hidrokarbon pada Air dan Sedimen di Perairan Sungai Donan, Segara Anakan Kabupaten Cilacap, Jawa Tengah
}

\author{
Fahrizal Dwi Amri*, Chrisna Adhi Suryono, Wilis Ari Setyati \\ Departemen IImu Kelautan, Fakultas Perikanan dan IImu Kelautan, Universitas Diponegoro \\ J. Prof H.Soedharto S H, Tembalang, Semarang, Jawa Tengah 50275 Indonesia \\ ${ }^{*}$ Corresponding author, e-mail : fahrizal2amri@gmail.com
}

\begin{abstract}
ABSTRAK : Industri besar yang berada di Cilacap salah satunya adalah industri minyak dan gas (MIGAS) PT. Pertamina Refinery Unit IV Cilacap, dimana lokasi ini berada di sekitar perairan Sungai Donan yang menjadi objek penilitian. Aktivitas industri yang berada di dekat perairan dapat menyebabkan perairan mengalami pencemaran. Senyawa hidrokarbon adalah salah satu bahan yang dapat menyebabkan pencemaran pada suatu perairan, senyawa ini merupakan senyawa dominan penyususun minyak bumi. Tujuan penelitian ini adalah mengetahui hubungan kandungan total hidrokarbon pada air dan sedimen di perairan Sungai Donan, Cilacap. Penelitian ini dilaksanakan di perairan Sungai Donan Kabupaten Cilacap pada bulan Februari 2019 - April 2019. Lokasi penelitian dibagi menjadi tiga stasiun yaitu Stasiun A (dekat hulu), B (muara Kali Anget), C (muara Sungai Donan). Sample yang diambil yaitu Air permukaan dan sedimen setiap stasiun dengan tiga kali pengulangan setiap stasiun. Kandungan total hidrokarbon pada air di Sungai Donan yang tertinggi berada di Stasiun C sebesar $2.07 \mathrm{mg} / \mathrm{L}$, kemudian di stasiun A sebesar 0.63 $\mathrm{mg} / \mathrm{L}$ dan kandungan yang terendah pada Stasiun B sebesar $0.22 \mathrm{mg} / \mathrm{L}$. Kandungan total hidrokarbon pada sedimen berbanding lurus dengan air, kandungan yang tertinggi terdapat pada stasiun C sebesar $574.39 \mathrm{mg} / \mathrm{kg}$, kemudian di stasiun A sebesar $497.11 \mathrm{mg} / \mathrm{kg}$, dan kandungan yang terendah di Stasiun B sebesar $261.40 \mathrm{mg} / \mathrm{kg}$. Kandungan total hidrokarbon pada air di semua stasiun masih di bawah batas ambang baku mutu, sedangkan kandungan pada sedimen di semua stasiun sudah melewati baku mutu yang sudah ditetapkan.
\end{abstract}

Kata Kunci : Hidrokarbon, sedimen, perairan

\section{The Correlation of Total Hydrocarbons in Water and Sediment in River Donan, Cilacap, Central Jawa}

ABSTRACT: One of the large oil and gas industry in Cilacap is PT. Pertamina Refinery Unit IV Cilacap, where the location is located around the waters of the Donan River which becomes the object of the research. Industrial activities near the water can cause pollution. Hydrocarbon compounds are one of the ingredients that can cause pollution to water. This compound is the dominant compound of petroleum. The purpose of this research is to know the total content of hydrocarbons in water and sediment in the waters of Donan River, Cilacap. This study was held in the Donan River waters of Cilacap Regency in February 2019-April 2019. The location used in this research is divided into three stations: $A$ station (near the upstream), B (Kali Anget estuary), $C$ (Donan River estuary). The Sample is the surface water and sediment in each station that is repeated three times. The total content of hydrocarbons in water of the highest Donan river was at $C$ station $2.07 \mathrm{mg} / \mathrm{L}$, then at station $A$ of $0.63 \mathrm{mg} / \mathrm{L}$ and the lowest content at station $B$ amounted to $0.22 \mathrm{mg} / \mathrm{L}$. Total hydrocarbon content in sediment is directly proportional to water. the highest content found at the $C$ station amounted to $574.39 \mathrm{mg} / \mathrm{kg}$, then at station $A$ of $497.11 \mathrm{mg} / \mathrm{kg}$, and the lowest content at station B amounted to $261.40 \mathrm{mg} / \mathrm{kg}$. The total content of hydrocarbons in water at all stations is still below the threshold of quality standards, while the content on the sediment at all stations has passed the quality standards that is already set.

Keywords: Hydrocarbon, sediment, waters.

\section{PENDAHULUAN}

Segara Anakan di Cilacap berdiri beberapa ndustri besar seperti industri kilang minyak Pertamina, industri ini berperan menampung dan mengolah minyak mentah menjadi produk BBM, 
non BBM, dan petrokimia. Limbah yang dihasilkan diduga mengandung senyawa hidrokarbon yang dapat masuk ke lingkungan perairan.

Dampak hidrokarbon pada perairan bisa sangat parah karena punya kecenderungan terakumulasi dalam jaringan ikan, moluska, kerang, dan mamalia lainnya (Rahmani, 2015). Senyawa hidrokarbon pada perairan dapat berasal dari tumpahan minyak, pengilangan, limbah kota dan kegiatan transportasi (kapal tanker dan pengiriman minyak) (Adeniji dkk., 2017). Penelitian yang dilakukan oleh Wokoma (2014), hidrokarbon ditemukan pada air dan sedimen di Sungai Bonny, Delta Niger, Nigeria. Hasil dari konsentrasi dalam air dan sedimen adalah 15,6 \pm $1,86-23,4 \pm 2,55 \mathrm{mg} / \mathrm{L}$ dan $1,403 \pm 80,61-3,755 \pm 113,14 \mathrm{mg} / \mathrm{kg}$. Penelitian yang sama juga dilakukan oleh Adeniji dkk., (2017) di Teluk Algoa, Eastern Cape, Afrika Selatan, hasil yang didapat menunjukkan bahwa total hidrokarbon bervariasi dari 45,07 hingga $307 \mu \mathrm{g} / \mathrm{L}$ dalam air dan 0,72-27,03 $\mathrm{mg} / \mathrm{kg}$ sedimen. Aderinola dkk., (2018) dalam penelitiannya di Sungai Badagry, konsentrasi rata-rata total hidrokarbon yang ditemukan dalam air dan sedimen sebesar 0,495 \pm $0,035 \mathrm{mg} / \mathrm{l}$ dan 12,090 $\pm 8,641 \mu \mathrm{g} / \mathrm{g}$. Pengujian kandungan minyak dan lemak sudah dilakukan oleh PT. Pertamina Refinery Unit IV Cilacap bekerja sama dengan Balai Besar Teknologi Pencegahan Pencemaran Industri (BBTPPI) Semarang pada bulan Februari dan Mei setiap tahun. Uji ini hanya dilakukan pada air permukaan Sungai Donan, tetapi uji pada sedimen belum dilakukan. Informasi mengenai kandungan hidrokarbon dalam perairan sangat dibutuhkan, khususnya pada perairan seperti Sungai Donan yang di sekitarnya terdapat industri kilang minyak dan pelabuhan yang berpotensi dapat meningkatkan konsentrasi hidrokarbon dalam perairan. Informasi yang di dapat dapat dibandingkan dengan baku mutu perairan yang sudah ditetapkan, apakah masih di bawah batas ambang atau sudah melewatinya.

Dampak yang ditimbulkan oleh pencemaran hidrokarbon di Sungai Donan menjadi dasar pertimbangan dilakukan penelitian ini, serta belum adanya penelitian yang dilakukan di perairan ini. Tujuan dari penelitian ini adalah untuk mengetahui korelasi kandungan hidrokarbon pada air dan sedimen di perairan Sungai Donan.

\section{MATERI DAN METODE}

Penelitian dilakukan pada bulan Februari 2019 di perairan Sungai Donan, Kabupaten Cilcacap. Materi penelitian ini adalah air dan sedimen yang kemudian dilakukan uji Kandungan total hidrokarbon. Pengambilan sampel dilakukan di tiga stasiun yang berbeda, dengan masingmasing stasiun dilakukan perulangan.tiga kali. Stasiun A terletak di dekat hulu Sungai Donan, Stasiun B terletak di muara Kali Anget yang menjadi saluran pembuangan limbah pertamina, dan Stasiun $\mathrm{C}$ terletak di muara Sungai Donan yang berdekatan dengan Pelabuhan Tanjung Intan. Pengambilan air permukaan dilakukan secara langsung, yaitu dengan mengambil langsung air menggunakan ember. Sampel sedimen yang diambil pada penelitian ini adalah sedimen dasar. Pengambilan sampel sedimen dasar menggunakan alat grab sampler.

\section{Analisis Sampel}

Sampel air dianalisis untuk diukur kandungan total hidrokarbon. Analisis yang digunakan menggunakan metode ektrak dengan pelarut n-Heksana. Metode ini berdasarkan petunjuk Environmental Monitoring \& Support Laboratory dalam EPA (1982).

$$
\mathrm{mg} / \mathrm{L} \text { minyak }=((\mathrm{A}-\mathrm{B}) / \mathrm{sampel}(\mathrm{ml})) \times 1000
$$

Keterangan : A = Berat erlenmeyer setelah diuapkan (gram); B = Berat erlenmeyer kosong (gram)

Sampel sedimen dinalisis untuk untuk mengukur kandungan total hidrokarbon pada sedimen. Prosedur analisis sedimen untuk uji kandungan total hidrokarbon berdasarkan petunjuk Environmental Monitoring \& Support Laboratory dalam EPA (1982) dengan menggunakan metode Soxhlet

$$
\mathrm{mg} / \mathrm{kg} \text { minyak }=((A-B) / \text { sampel }(\text { gram })) \times 1000
$$

Keterangan : A = Berat erlenmeyer setelah diuapkan (gram); $\mathrm{B}=$ Berat erlenmeyer kosong (gram) 


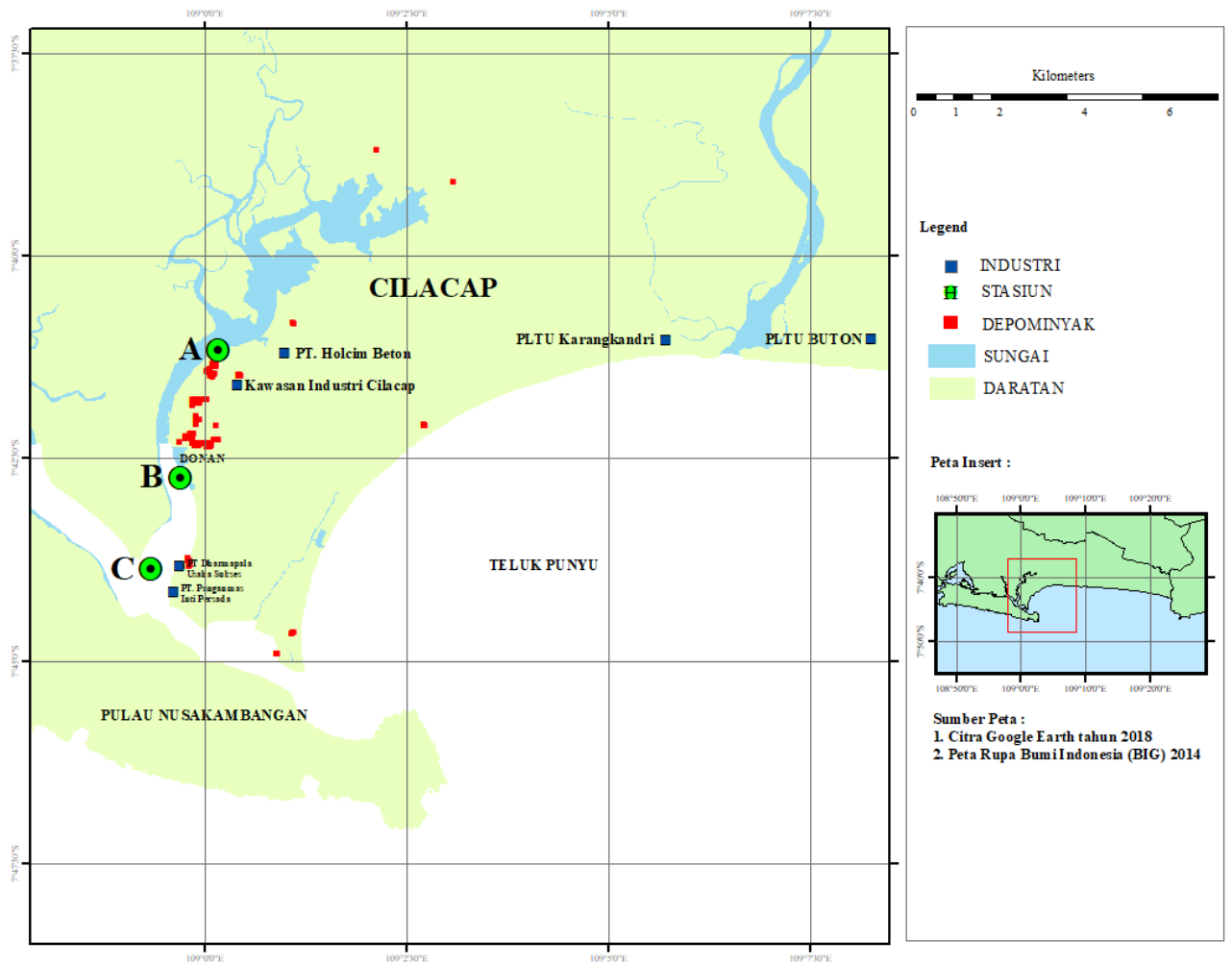

Gambar 1. Peta Lokasi Pengambilan Sampel di Perairan Sungai Donan, Kabupaten Cilacap HASIL DAN PEMBAHASAN

Hasil pengukuran kandungan total hidrokarbon pada air dan sedimen bervariasi dari 0.22 $2.07 \mathrm{mg} / \mathrm{L}$ dan $6.12-574.39 \mathrm{mg} / \mathrm{kg}$. Kandungan yang tertinggi berada di Stasiun A dan yang terendah pada Stasiun B untuk detailnya dapat dilihat di Tabel 1.

Tabel 1. Kandungan Total Hidrokarbon pada Air dan Sedimen di Perairan Sungai Donan

\begin{tabular}{cccc}
\hline Stasiun & Perulangan & $\begin{array}{c}\text { Total Hidrokarbon dalam Sedimen } \\
(\mathrm{mg} / \mathrm{kg})\end{array}$ & $\begin{array}{c}\text { Total Hidrokarbon dalam } \\
\text { Air }(\mathrm{mg} / \mathrm{L})\end{array}$ \\
\hline $\mathrm{A}$ & 1 & 341.94 & 0.14 \\
& 2 & 601.96 & 0.42 \\
& 3 & 547.44 & 1.33 \\
$\mathrm{~B}$ & rata-rata & 497.11 & 0.63 \\
& 1 & 404.90 & 0.09 \\
& 2 & 373.18 & 0.33 \\
& 3 & 6.12 & 0.24 \\
$\mathrm{C}$ & rata-rata & 261.40 & 0.22 \\
& 1 & 363.04 & 0.67 \\
& 2 & 731.04 & 3.89 \\
& 3 & 629.10 & 1.66 \\
& rata-rata & 574.39 & 2.07 \\
\hline
\end{tabular}

Keterangan : Stasiun A = dekat hulu Sungai Donan; Stasiun B = muara Kali Anget; Stasiun C = muara Sungai Donan 
Pengukuran kandungan hidrokarbon pada air dan sedimen tertinggi pada stasiun $\mathrm{C}$, hal tersebut dapat disebabkan pada stasiun C berlokasi dekat dengan Pelabuhan Tanjung Intan Cilacap. Stasiun C berlokasi pada hilir Sungai Donan yang bermuara di Selat Nusakambangan. Stasiun C juga berada dekat dengan pelabuhan Tanjung Intan Cilacap. Transportasi perairan dan aktivitas bongkar muat pada pelabuhan cilacap dapat menjadi sumber perairan tersebut mengandungan hidrokarbon. Moslen dan Miebaka (2017) melaporkan hidrokarbon dengan konsentrasi tinggi dalam sedimen ditemukan pada muara sungai, pelabuhan, teluk dan di daerah pantai yang menerima pembuangan industri dan perkotaan. Ukuran tanker pada kapal tanker yang semakin besar, maka diperkirakan masuknya polutan minyak ke laut juga semakin besar (Mukhtasor, 2007). Polutan tersebut banyak di dominasi oleh minyak yang sebagian besar kandungannya adalah hidrokarbon. Sumber lapisan minyak lainnya adalah proses perawatan kapal (Docking), saat proses ini sisa bahan bakar yang ada di dalam tangki harus dikeluarkan semua agar tidak terjadi kebakaran atau meledak.

Stasiun B berlokasi pada muara Kali Anget yang bermuara pada Sungai Donan bagian tengah. Kali Anget membawa air limbah hasil dari IPAL Pertamina Refinery Unit IV Cilacap sebesar $187.136 \mathrm{~kg} / \mathrm{jam}$ dan debit air limbah pada Kali Anget sebesar $10.077 \mathrm{~m} 3 /$ detik. Kandungan hidrokarbon pada stasiun ini dapat disebabkan oleh adanya aktivitas mesin-mesin kilang yang dibawa oleh air pendingin. Menurut Wokomo (2014), menyatakan bahwa industri Minyak Bumi berkontribusi besar terhadap dengradasi perairan dan pencemaran lingkungan. Minyak dari industri perminyakan memasuki lingkungan akuatik melalui beberapa sumber seperti pembakaran gas, pembuangan minyak pelumas bekas, pencucian dari tangki minyak, kebocoran dari kapal laut dan mesin kapal, sabotase, erosi dan lari dari minyak tanah tercemar, rembesan, kilang efluen, pecahnya garis aliran / instalasi yang tidak terawat, kesalahan pemeliharaan dan rekayasa. Kandungan total hidrokarbon pada air dan sedimen di stasiun A lebih tinggi dibandingkan dengan stasiun B, hal itu dapat disebabkan oleh pergerakan arus pada Sungai Donan yang menuju ke daerah hulu. Pergerakan arus ini berperan besar dalam proses pengangkutan hidrokarbon yang semula berada di stasiun B terbawa ke stasiun A. Stasiun A berlokasi dekat dengan hulu dari Daerah Aliran Sungai Donan. Sumber kandungan hidrokarbon pada lokasi ini dapat disebabkan oleh pergerakan arus dan gelombang pasang surut, sehingga membawa minyak yang berada dari Stasiun B dan C sebagian ikut terbawa menuju Stasiun A, hal ini sesuai dengai pengukuran arus secara langsung pada lokasi yang menunjukkan kecepatan arus rata-rata adalah $1 \mathrm{~m} / \mathrm{s}$ dengan arah ke utara menuju hulu sungai. Penyebaran minyak di perairan bergerak sesuai dengan arus, minyak hanya tersebar di sekitar muara Sungai Donan, kemudian mulai menyebar semakin jauh ke arah hulu sungai (Wibowo, 2017). Hasil pengukuran arus di alur pelayaran Cilacap 1992 oleh Dishidros TNI-AL pada perairan tersebut, arus pasut lebih dominan dan arus nonpasut relatif lebih rendah. Massa air laut pada saat pasang akan mengalir dari Samudera Hindia masuk melalui perairan, sehingga akan mendorong hidrokarbon menuju arah hulu. Arus di sekitar alur pelayaran yang berasal dari hulu perairan Sungai Donan sangat kecil, karena pada dasarnya perairan tersebut bukan perairan sungai.

Hubungan antara kandungan total hidrokarbon pada air dan kandungan total hidrokarbon pada sedimen ditunjukan melalui grafik yang ditunjukan pada gambar 2. Hasil menunjukan bahwa persamaan regresi pada kandungan total hidrokarbon pada air dan sedimen di perairan Sungai Donan adalah $Y=0.0039 x-0.7498$, dimana variabel y adalah kandungan total hidrokarbon pada sedimen dan variabel $\mathrm{x}$ adalah kandungan total hidrokarbon pada air. Hasil tersebut memberikan informasi bahwa nilai dari persamaan regresi tersebut adalah positif yang berarti semakin meningkat kandungan total hidrokarbon pada air maka kandungan total hidrokarbon pada sedimen juga akan meningkat. Hal ini didukung dengan hasil penelitian yang dilakukan oleh Dumka dan Kingdom (2018) di Sungai Otamiri, Nigeria, dimana hubungan kandungan total hidrokarbon pada air dan sedimen juga bernilai positif. Dari uji regresi yang telah dilakukan menunjukkan nilai $\mathrm{P}=$ $0.04<0.05$, maka kandungan total hidrokarbon pada air akan berpengaruh juga pada kandungan total hidrokarbon pada sedimen. Hasil diatas juga menampilkan nilai koefisien determinasi $R^{2}=$ 0.4647 dan nilai koefisien korelasi $r=0.6816$. Menurut Ndruru dkk., (2014), besarnya nilai koefisien determinasi adalah berkisar $0<R^{2}<1$, artinya jika $R^{2}$ mendekati 1 maka dapat dikatakan pengaruhnya akan semakin besar. Nilai koefisien korelasi pada Gambar 2. menunjukkan hubungan yang kuat karena berada pada nilai 0.6-0.799 dan nilai koefisien determinasi 
menunjukkan hidrokarbon pada air memberikan pengaruh $46 \%$ pada kandungan hidrokarbon pada sedimen, sedangkan 54\% lainnya adalah faktor lain. Penyebaran minyak bumi di laut banyak dipengaruhi oleh beberapa faktor seperti arus, angin, dan gelombang (Widhayanti, 2015).

Kandungan total hidrokarbon pada sedimen lebih besar dibandingkan dengan yang ada di air, hal ini dapat disebabkan oleh sifat persebaran minyak bumi pada perairan. Persebaran minyak bumi pada perairan mempunyai sifat antara lain sedimentasi dan penguapan. Menurut Wokoma (2014), nilai sedimen umumnya lebih tinggi dari dalam air. Ini bisa dikaitkan dengan fakta fraksi minyak bumi hidrokarbon yang lebih berat biasanya melewati kolom air dan mengendap ke bawah, sementara yang lain bercampur dengan air dan menembus sedimen yang mendasarinya. Umumnya, fraksi hidrokarbon aromatik lebih ringan dan menguap dengan cepat, terutama selama periode angin kencang dan aktivitas gelombang. Kandungan pada sedimen lebih besar dengan yang ada di air juga disebabkan pergerakan arus pada perairan Sungai Donan yang relatif pelan yaitu sekitar $1 \mathrm{~m} / \mathrm{s}$, hal tersebut bisa membuat proses sedimentasi hidrokarbon cepat dan mengakibatkan kandungan hidrokarbon pada sedimen lebih tinggi dibandingkan dengan air. Hal ini sesuai dengan hasil penelitian yang dilakukan oleh Dumka dan Kingdom (2018) di Sungai Otamiri, Nigeria, dimana hasil kandungan total hidrokarbon dalam air permukaan berkisar antara 1,51 hingga 19,38 mg/L dan dalam sedimen berkisar antara 16,01 hingga 136,04 mg/kg.

Kandungan total hidrokarbon pada air pada stasiun A dan B masih di bawah baku mutu yang mengatur batasan maksimal konsentrasi minyak dan lemak yang diperbolehkan untuk air limbah. Baku mutu yang ditetapkan dalam Peraturan Daerah Provinsi Jawa Tengah No. 5 Tahun 2012 tentang Baku Mutu Air Limbah, kisaran konsentrasi yang disyaratkan adalah $2-25 \mathrm{mg} / \mathrm{L}$. Baku mutu yang telah diatus dalam Keputusan Menteri Lingkungan Hidup No.51 Tahun 2004 tentang Baku Mutu Air Laut, telah menetapkan Konsentrasi maksimal yang dibolehkan air limbah industri yaitu $1 \mathrm{mg} / \mathrm{L}$. Perairan lain seperti air laut pada perairan pelabuhan dipersyaratkan mempunyai konsentrasi minyak dan lemak maximum sebesar $5 \mathrm{mg} / \mathrm{L}$. Pada stasiun $\mathrm{C}$ kandungan total hidrokarbon dalam air masih di bawah baku mutu yang sudah ditetapkan. Kandungan total hidrokarbon pada sedimen pada semua stasiun sudah melewati baku mutu yang sudah ditetapkan, dimana kandungan minyak dalam sedimen di perairan yang telah ditentukan oleh National Academy of Sciences (1975) yaitu 1-100 ppm.

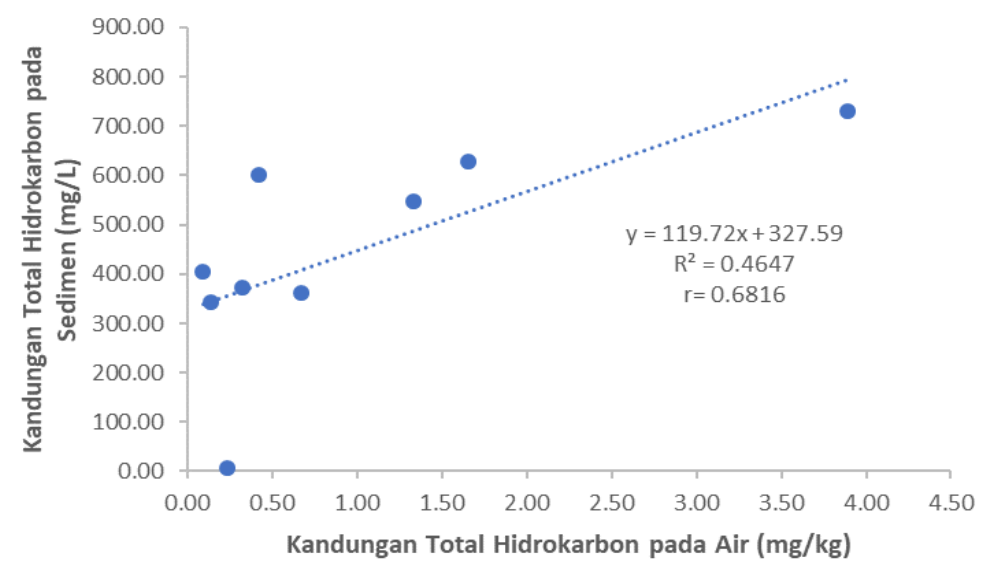

Gambar 2. Hubungan Kandungan Total Hidrokarbon pada Air dan Sedimen di Perairan Sungai Donan.

\section{KESIMPULAN}

Hasil pengukuran kandungan total hidrokarbon pada air dan sedimen bervariasi dari 0.22 $2.07 \mathrm{mg} / \mathrm{L}$ dan 6.12 - $574.39 \mathrm{mg} / \mathrm{kg}$, korelasi antara kandungan total hidrokarbon pada air dan sedimen menunjukkan hubungan kuat dengan nilai positif yang berarti semakin meningkat kandungan total hidrokarbon pada air maka akan meningkat juga kandungan total hidrokarbon pada sedimen di perairan Sungai Donan. 


\section{UCAPAN TERIMA KASIH}

Artikel ini merupakan bagian dari skripsi yang berjudul "Analisis Kandungan Total Hidrokarbon pada Air dan Sedimen di Perairan Sungai Donan, Kabupaten Cilacap", untuk memperoleh gelar Sarjana Strata Satu Program Studi IImu Kelautan, Fakultas Perikanan dan IImu Kelautan Universitas Diponegoro.

\section{DAFTAR PUSTAKA}

Adeniji, A.O., Omobola, O.O. \& Anthony I.O., 2017., Petroleum Hydrocarbon Profiles of Water and Sediment of Algoa Bay, Eastern Cape, South Africa. International Journal of Environmental Research and Public Health. 14(1):1-21.

Aderinola, O.J., Mekuleyi, G.O. \& Whenu, O.O., 2018., Total and Polyaromatic Hydrocarbons in Water, Sediment, Fin and Shellfishes from Badagry Creek and Ologe Lagoon, Lagos, Nigeria. Journal of Applied Sciences and Environmental Management. 22(5):675- 680.

Dumkaand, N.J. \& Kingdom, A., 2018., Total Hydrocarbon Concentrations (THC) in Surface Water, Sediments and Biota from Otamiri River, Rivers State, Nigeria. International Journal of Chemical Studies. 6(3):2743-2748.

Environmental Protection Agency (EPA)., 1982., Methods For Chemical Analysis of Water and Wastes. Environmental Monitoring and Support Laboratory. Cincionoti, Ohio, 552p

Keputusan Menteri Negara Lingkungan Hidup Nomor 51 Tahun 2004 tentang Baku Mutu Air Laut. $5 \mathrm{hlm}$.

Moslen, M. \& Miebaka, C.A., 2017., Hydrocarbon Contamination of Sediments in the Niger Delta Region: a case study of the Azuabie creek,upper reaches of the Bonny Estuary, Nigeria. IOSR Journal of Environmental Science, Toxicology and Food Technology. 11(1):26-32.

Mukhtasor., 2007., Pencemaran Pesisir dan Laut. PT Pradnya Paramita, Jakarta, 322hlm.

National Academy of Sciences., 1975., Petroleum in the marine environment. National Academy of Sciences, Washington, D.C, 107p.

Ndruru, R.E., Situmorang, M. \& Tarigan, G.,2014.,Analisa Faktor-Faktor Yang Mempengaruhi Hasil Produksi Padi Di Deli Serdang. Jurnal Saintia Matematika. 2(1):71-83.

Peraturan Daerah Provinsi Jawa Tengah Nomor 5 Tahun 2012 tentang Perubahan Atas Peraturan Daerah Provinsi Jawa Tengah Nomor 10 Tahun 2004 tentang Baku Mutu Air Limbah. 13hlm.

Rahmani, A., 2015., Kandungan dan Sumber Asal Senyawa Polisiklik Aromatik Hidrokarbon (PAH) dalam Sedimen di Perairan Pakis Jaya, Kabupaten Karawang. Jurnal Akuatika. 6 (2):95-106.

Wibowo, M., 2017., Pemodelan Sebaran Pencemaran Tumpahan Minyak di Perairan Cilacap. Journal of Management of Aquatic Resources. 19(2):1-12.

Widhayanti, A., Ismanto, A. \& Yulianto, B., 2015., Sebaran Tumpahan Minyak dengan Pendekatan Model Hidrodinamika dan Spill Analysis di Perairan Cilacap, Jawa Tengah. Jurnal Oseanografi. 4(4):641-650.

Wokoma, O.A.F., 2012., Levels of Total Hydrocarbon in Water and Sediment of A Polluted Tidal Creek, Bonny River, Niger Delta, Nigeria. International Journal of Scientific \& Technology Research. 3(12):351-354. 